\title{
Lunar phase does not influence perioperative complications in total hip arthroplasty
}

Andreas Ficklscherer, Alexander Angermann, Patrick Weber, Bernd Wegener, Matthias Pietschmann, Peter Müller

Department of Orthopedics, Ludwig-Maximilians-University of Munich, Germany

Submitted: 13 March 2011

Accepted: 18 August 2011

Arch Med Sci 2012; 8, 1: 111-114

DOI: 10.5114/aoms.2012.27290

Copyright (C 2012 Termedia \& Banach

\section{Abstract}

Introduction: Lunar calendars, publishing recommendations for daily life, are gaining more and more attention in Germany, where $10.5 \%$ of the population believe in lunar effects on disease. A widespread and often heard belief is that a full moon has the most negative effects on surgical outcome. The present study evaluates the effects of lunar phase on perioperative complications in total hip arthroplasty.

Material and methods: We performed a retrospective study with 305 patients being provided with a primary hip arthroplasty. To identify possible influences of the lunar phase on perioperative complications we investigated data such as operation length, blood loss and course of C-reactive protein that were collected during the patients' stay in the hospital and allocated them to moon illumination.

Results: There were no significant differences in all collected data concerning the lunar phase $(p>0.05)$. Although not statistically significant, there were fewer operations during the full moon phase.

Conclusions: Therefore there is no evidence that lunar phase has an effect on perioperative complications in total hip arthroplasty. Fewer, though not significantly fewer, operations were performed during the full moon phase. Although this was not a prospective randomized trial, the statistical magnitude of the results does not support any recommendations for scheduling patients for total hip arthroplasty at any particular day of the lunar phase.

Key words: lunar phase, hip arthroplasty, perioperative complications.

\section{Introduction}

The belief that the lunar cycle has an influence on human health is old and widespread, and the mass media encourage pertinacious rumours that it also influences the medical progress in several medical procedures and long-term results [1]. These ideas are supported by some medical studies $[2,3]$ which have found a connection between the lunar phase and certain medical phenomena.

$10.5 \%$ of the German population believe in lunar effects on man [4]. In addition, an increasing number of books, guides and astrological tables recommend a lifestyle according to the moon and therefore advise certain days to see the hairdresser (in order to obtain good hair), mow the lawn (for thicker grass) or even see the doctor for a special procedure (to prevent complications). In a survey conducted at our hospital, $21.3 \%$ of
Corresponding author:

Dr. Andreas Ficklscherer Department of Orthopedics Ludwig-Maximilians-University of Munich

Marchioninistr. 15 81377 Munich, Germany Phone: 00498970950 E-mail: andreas.ficklscherer@ med.uni-muenchen.de 
our in-hospital patients own a moon calendar and schedule their appointments, whether it is the hairdresser or an operation, depending on lunar cycles. As a result we increasingly see patients with distinct, moon-dependent ideas about their surgery date. This can sometimes lead to rearrangements on the operating schedule at short notice and decline of workload on specific days as well as dissatisfaction of the patient if a certain date is unavailable.

Previously published studies investigating lunar effects examined if certain medical phenomena, e.g. myocardial infarction, accumulate on specific days [5-7] or considered several surgical procedures at a time [4]. So far there is no such study evaluating possible effects of the lunar cycle on perioperative complications in a single standardized procedure. Because total hip arthroplasty is one of our major procedures which can be timed by the patient, the present retrospective study investigated the association of the lunar cycle and total hip arthroplasty.

\section{Material and methods}

We performed a retrospective study with 305 patients being provided with a primary total hip arthroplasty. Patients with a prior arthroplasty, no matter which joint, were excluded. Subjects were 19 to 91 years of age (mean $62.61 \pm 13.97$ years) and mainly women ( $n=168$ or $55.1 \%$ ). The operations were all performed by 4 senior physicians who were the chief or a member of the arthroplasty department at the time of surgery. Moon illumination was scaled into 4 periods: full moon, new moon, waxing moon and waning moon.

To identify possible influences of the lunar cycle on perioperative complications, we investigated data collected during the patients' stay in the hos-

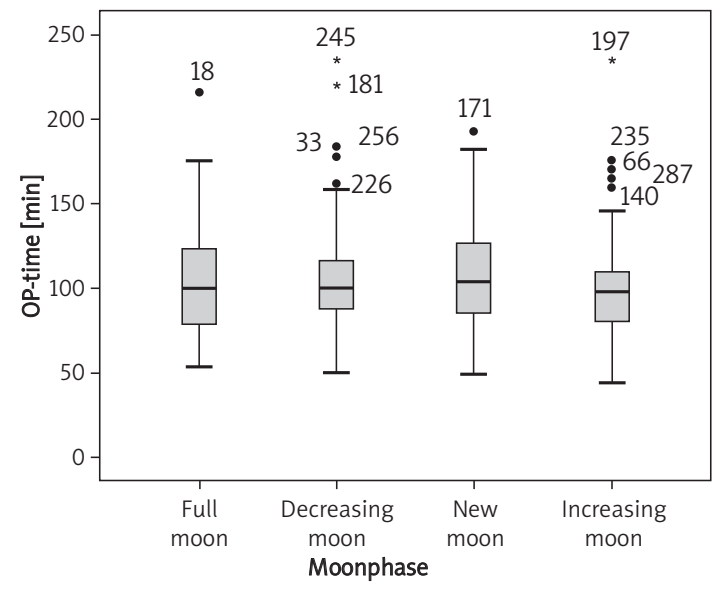

Figure 1. Mean operation length with SD during full, decreasing, new and increasing moon. No significant difference between the groups $(p>0.05)$. Numbers are showing outliers pital and allocated them to moon illumination. The following data were acquired: duration of surgery, loss of haemoglobin, temperature profile, differences in preoperative and postoperative leukocytes and C-reactive protein. Time spent in hospital postoperatively was also included. The technical value of the arthroplasty was included by measuring the varus/valgus-angle.

For statistical analysis, Student's $t$ test was used. A $p$ value less than 0.05 was considered significant.

\section{Results}

Sixty-one operations (20\%) were performed during full moon, 80 (26.2\%) during new moon, 77 (25.2\%) during decreasing moon and 87 (28.5\%) during increasing moon. The mean age and gender did not differ significantly in the 4 groups $(p>0.05)$. The mean operation length was $103.62 \mathrm{~min}$ (SD $32.05 \mathrm{~min}$ ) during full moon, $103.91 \mathrm{~min}$ (SD 33.56 min) during decreasing moon, $106.16 \mathrm{~min}$ (SD 29.44 min) during new moon and $99.2 \mathrm{~min}$ (SD $29.96 \mathrm{~min}$ ) during increasing moon (Figure 1). The mean loss of haemoglobin was $2.77 \mathrm{~g} / \mathrm{dl}(\mathrm{SD} 1.47 \mathrm{~g} / \mathrm{dl}$ ) in full moon, $2.28 \mathrm{~g} / \mathrm{dl}$ (SD $1.29 \mathrm{~g} / \mathrm{dl}$ ) in decreasing moon, $2.4 \mathrm{~g} / \mathrm{dl}(\mathrm{SD} 1.65 \mathrm{~g} / \mathrm{dl})$ during increasing moon and $2.4 \mathrm{~g} / \mathrm{dl}$ (SD $1.49 \mathrm{~g} / \mathrm{dl}$ ) during new moon (Figure 2). Eighty patients received erythrocyte concentrates postoperatively, but these were distributed equally over the moon phases. See Figure 3 for white blood cell (WBC) differences in the four groups. A total of 25 major complications such as leg length discrepancy (15), femur fracture (6), pulmonary embolism (2), lesion of the sciatic nerve (1) and lesion of the obturator nerve (1) were found. The mean varus/valgus angle was $0.28^{\circ}\left(\mathrm{SD} 1.05^{\circ}\right)$ varus during full moon, $0.13^{\circ}\left(\mathrm{SD} 1.17^{\circ}\right)$ varus during decreasing moon, $0^{\circ}\left(\mathrm{SD} 1.04^{\circ}\right)$ varus/valgus during new moon and $0.17^{\circ}\left(\mathrm{SD} 1.07^{\circ}\right)$ varus during increasing

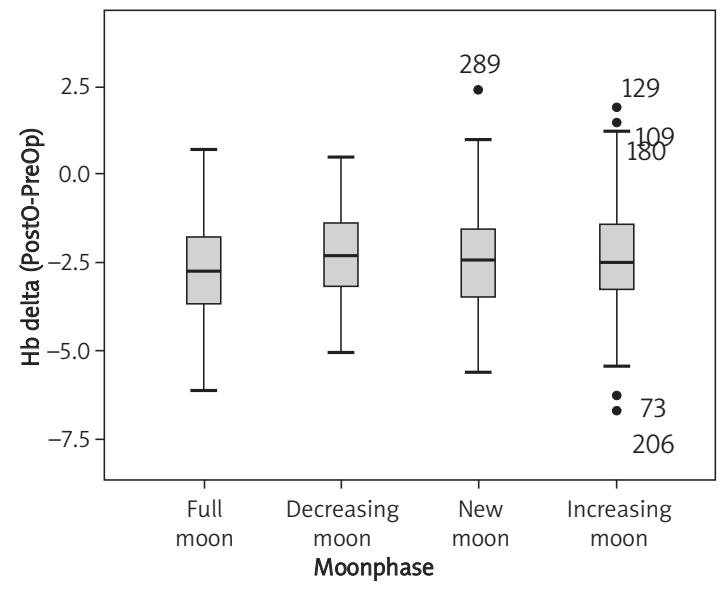

Figure 2. Mean loss of haemoglobin with SD 
moon. There were no significant differences in all collected data concerning the lunar phase $(p>0.05)$.

\section{Discussion}

The effect of lunar phase has been studied for psychiatric services, homeopathy, delivery, trauma, traffic accidents, myocardial infarction and crime. There are several studies which have found an association between moon phase and crime, myocardial infarction, delivery and general practice consultation [2, 8-10]. However, there are as many studies which demonstrate that there is no relationship at all between medical phenomena and lunar phases $[5,6,11]$. Because $21.3 \%$ of our in-hospital patients strongly believe in lunar influences and often demand specific surgery dates dependent on the lunar cycle, we conducted this study. As far as we know, there are no studies evaluating possible effects of the lunar cycle on perioperative complications in a single standardized procedure. Because total hip arthroplasty is one of our major procedures which in addition can be scheduled by the patient, the present retrospective study investigated the association of the lunar cycle and total hip arthroplasty.

We evaluated data of 305 patients which were collected pre-, intra- and postoperatively and allocated them to the 4 lunar phases: full moon, new moon, waxing moon and waning moon. None of the collected parameters differed significantly from the other $(p>0.05)$. In addition, we only observed 25 major complications such as leg length discrepancy (15), femur fracture (6), pulmonary embolism (2), lesion of the sciatic nerve (1) and lesion of the obturator nerve (1). The number of minor complications was even smaller. None of them differed significantly among the 4 groups.

The results of our study are in agreement with other recently published studies investigating the effect of lunar phase on outcome for patients after operations. Outcome of breast cancer patients was not different when the timing of breast cancer surgery during the lunar cycle was considered [12]. In a survey concerning postoperative nausea and vomiting (PONV) an unexpected high number of participants stressed the impact of environmental factors, e.g., weather or lunar phase. However, in 2488 patients who were followed up for $24 \mathrm{~h}$ postoperatively the days with a high or low incidence of PONV were equally distributed within the four phases of the moon [13]. Others observed no correlation of lunar phases with acute coronary events leading to myocardial infarction or sudden death in 1240 patients [1]. At the University of Graz, Austria, nearly 15000 consecutive inpatients with surgical procedures including abdominal, vascular, cardiac, thoracic, plastic and orthopaedic operations showed

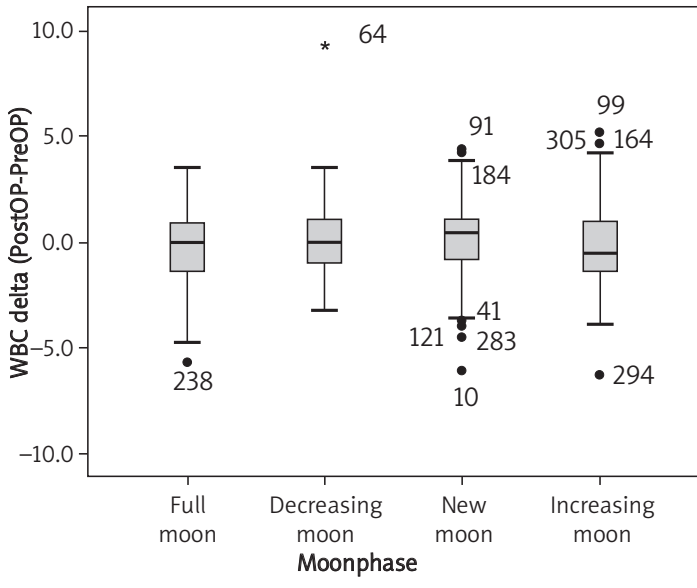

Figure 3. Difference pre- and postoperatively in white blood cell count as a marker of inflammation

no relationship between perioperative mortality and lunar phase [14].

Our analysis demonstrated no predictable influence of the lunar phase on perioperative complications. Although this was not a prospective randomized trial, the statistical magnitude of the results does not support any recommendations for scheduling patients for total hip arthroplasty at any particular day of the lunar phase.

\section{References}

1. Eisenburger $P$, Schreiber W, Vergeiner $G$, et al. Lunar phases are not related to the occurrence of acute myocardial infarction and sudden cardiac death. Resuscitation 2003; 56: 187-9.

2. Sha LR, Xu NT, Song XH, Zhang LP, Zhang Y. Lunar phases, myocardial infarction and hemorrheological character. A Western medical study combined with appraisal of the related traditional Chinese medical theory. Chin Med J (Engl) 1989; 102: 722-5

3. Mikulecky $M$, Valachova A. Lunar influence on atrial fibrillation? Braz J Med Biol Res 1996; 29: 1073-5.

4. Holzheimer RG, Nitz C, Gresser U. Lunar phase does not influence surgical quality. Eur J Med Res 2003; 8: 414-8.

5. Gutierrez-Garcia JM, Tusell F. Suicides and the lunar cycle. Psychol Rep 1997; 80: 243-50.

6. Waldhoer T, Haidinger G, Vutuc C. The lunar cycle and the number of deliveries in Austria between 1970 and 1999. Gynecol Obstet Invest 2002; 53: 88-9.

7. Wolbank S, Prause G, Smolle-Juettner F, et al. The influence of lunar phenomena on the incidence of emergency cases. Resuscitation 2003; 58: 97-102.

8. Ghiandoni G, Secli R, Rocchi MB, Ugolini G. Does lunar position influence the time of delivery? A statistical analysis. Eur J Obstet Gynecol Reprod Biol 1998; 77: 47-50.

9. Neal RD, Colledge M. The effect of the full moon on general practice consultation rates. Fam Pract 2000; 17 : 472-4.

10. Thakur CP, Sharma D. Full moon and crime. Br Med J (Clin Res Ed) 1984; 289: 1789-91.

11. Gorvin JJ, Roberts MS. Lunar phases and psychiatric hospital admissions. Psychol Rep 1994; 75: 1435-40. 
12. Peters-Engl C, Frank W, Kerschbaum F, Denison U, Medl M, Sevelda P. Lunar phases and survival of breast cancer patients: a statistical analysis of 3,757 cases. Breast Cancer Res Treat 2001; 70: 131-5.

13. Eberhart LH, Jakobi G, Winterhalter M, Georgieff M. Impact of environmental factors on the incidence of posteropative nausea and vomiting. Influence of the weather and cycle of the moon [German]. Anasthesiol Intensivmed Notfallmed Schmerzther 2000; 35: 635-40.

14. Smolle J, Prause G, Kerl H. A double-blind, controlled clinical trial of homeopathy and an analysis of lunar phases and postoperative outcome. Arch Dermatol 1998; 134: $1368-70$ 